\title{
Response Surface Methodology to Optimize Degradation on Phenol by Pseudomonas stutzeri ZH-1
}

\author{
Yong Yan, Qingping $\mathrm{Hu}^{*}$ \\ College of Life Science, Shanxi Normal University, Linfen, China \\ Email: *hqp72@163.com
}

How to cite this paper: Yan, Y. and $\mathrm{Hu}$, Q.P. (2020) Response Surface Methodology to Optimize Degradation on Phenol by Pseudomonas stutzeri ZH-1. Open Access Library Journal, 7: e6952.

https://doi.org/10.4236/oalib.1106952

Received: October 30, 2020

Accepted: November 24, 2020

Published: November 27, 2020

Copyright $\odot 2020$ by author(s) and Open Access Library Inc.

This work is licensed under the Creative Commons Attribution International License (CC BY 4.0).

http://creativecommons.org/licenses/by/4.0/

\section{(c) (i) Open Access}

\begin{abstract}
In order to obtain the optimal conditions for the degradation of phenol by Pseudomonas stutzeri $\mathrm{ZH}-1$, based on the single factor experiment, the Box Behnken design test of Response Surface Method was used. Four variables of glucose concentration $(0.4,0.6,0.8 \mathrm{~g} / \mathrm{L})$, inoculation concentration $(3 \%, 5 \%$, $7 \%), \mathrm{pH}(6,7,8)$ and temperature $\left(35^{\circ} \mathrm{C}, 37.5^{\circ} \mathrm{C}, 40^{\circ} \mathrm{C}\right)$ were used to identify the significant effects and interactions in the batch studies. A second order polynomial regression model, has been developed using the experimental data. The experimental values were in good agreement with the predicted values, and the correlation coefficient was found to be 0.9901 . Optimum conditions of the variables for the growth of Pseudomonas stutzeri $\mathrm{ZH}-1$ and for maximum biodegradation of phenol are glucose concentration $(0.7 \mathrm{~g} / \mathrm{L})$, inoculation concentration $5 \%, \mathrm{pH}=7$ and temperature $37^{\circ} \mathrm{C}$ with maximum phenol degradation rate of $89.62 \%$.
\end{abstract}

\section{Subject Areas}

Biochemistry, Bioengineering

\section{Keywords}

Response Surface Methodology, Box-Behnken, Phenol Degradation, Pseudomonas stutzeri

\section{Introduction}

Phenol compounds are among the most common pollutants. Phenol and its derivatives are the most representatives of the toxic organic pollutants, being produced in several industries and operations such as gas and coke oven industries, 
polymeric resin production, petroleum refineries, fiber glass units, pharmaceuticals, explosive manufacturing, plastic and varnish industries, and textile industries, making use of organic dyes, smelting and related metallurgical operations, etc. [1] [2]. The U.S. Environmental Protection Agency (EPA) has listed phenol as a major pollutant with toxicity to aquatic microorganisms and malodors imparted at very low concentrations $(0.005 \mathrm{mg} / \mathrm{L})$ [3]. Phenol is toxic upon ingestion, contact or inhalation and it is recommended that human exposure to phenol not exceed $20 \mathrm{mg}$ in an average day [4]. Also, phenol is toxic to fish and can be lethal at concentrations of $5-25 \mathrm{ppm}$. Additionally, concentrations as low as $0.1 \mathrm{ppm}$ can taint the taste of fish. Due to their toxicity to microorganisms, phenol and its derivatives may often cause the breakdown of waste water treatment plants by inhibition of microbial growth [5]. Therefore, treatment of phenol effluents is critical to maintaining both human and wildlife environments.

Different chemical and biological treatment technologies have been employed for the reduction of phenol content in industrial waste water. The chemical technologies have proven to be costly and produce secondary toxic pollutants. Thus, the biological treatments become a favor-able alternative because of their simplicity of operation, cost effectiveness, and it can potentially turn toxic materials into harmless products [6] [7]. Therefore, there is a considerable attention of many researchers in the isolation of microbes able to thrive on high concentrations of phenols [8]. Pseudomonas sp were screened and the species (P. puti$d a)$ that degraded phenol in the shortest period of time and that which had high tolerance limit was selected for adaptation. Growth can be inhibited not by just the presence of toxic compounds but by the availability of micro and macro nutrients [9]. Therefore, it was thought worthwhile to study the effect of different media and to consider various environmental factors. Phenol biodegradation is sensitive to many factors such as $\mathrm{pH}$, incubation periods, carbon and nitrogen sources, and enormous efforts in several studies have been made to obtain the optimal conditions that increase the efficiency of phenol-degrading bacteria [10].

The objective of the present study is to optimize the process parameters (temperature, $\mathrm{pH}$, etc) for enhanced phenol degradation by Pseudomonas stutzeri $\mathrm{ZH}-1$ using Response Surface Methodology. In the present investigation the parameters affecting the degradation of phenol were identified and Box-Behnken design model was performed to predict the (\%) degradation of phenol. The Response Surface Methodology using the Box-Benhken Design of [11] experiments was used to develop a mathematical correlation between glucose concentration, inoculation concentration, $\mathrm{pH}$ and temperature and degradation of phenol.

\section{Materials and Methods}

\subsection{Microorganism}

P. stutzeri ZH-1 was originally isolated and identified from Fenhe River (in Shanxi Province, China). After being grown on the solidified Beef extract-peptone me- 
dium containing (per liter): $5.0 \mathrm{~g}$ beef extract, $10.0 \mathrm{~g}$ peptone, $5.0 \mathrm{~g} \mathrm{NaCl}, 18.0 \mathrm{~g}$ bacto-agar and $1000 \mathrm{~mL}$ tap water, the bacteria strain was stored at $-80^{\circ} \mathrm{C}$ in $30 \%(w / v)$ glycerol [12].

\subsection{Culture Medium and Inoculum Preparation}

The mineral salt medium (MSM) contained (g/L) [13]: study consisted of the following components (per liter): $\mathrm{K}_{2} \mathrm{HPO}_{4} 1.5 \mathrm{~g}, \mathrm{NaH}_{2} \mathrm{PO}_{4} 1.5 \mathrm{~g},\left(\mathrm{NH}_{4}\right)_{2} \mathrm{SO}_{4} 2.0$ g, $\mathrm{MgSO}_{4} 0.2 \mathrm{~g}, \mathrm{CaCL}_{2} 0.01 \mathrm{~g}, \mathrm{FeSO}_{4} 0.001 \mathrm{~g}$, the concentrations of phenol and culture conditions were adjusted following the subsequent experiments. The initial $\mathrm{pH}$ of all the mediums mentioned above was adjusted to 7.2 - 7.5.

A primary culture was prepared by transferring two loops full of microorganisms from an agar slant culture into $100 \mathrm{~mL}$ of feed medium containing $20 \mathrm{ml}$ of mineral salt medium and $80 \mathrm{ml}$ of $50 \mathrm{mg}$ phenol solution in a $250 \mathrm{~mL}$ erlenmeyer conical flask. This was then incubated in gyratory shaker for $48 \mathrm{~h}$ at a temperature of $35^{\circ} \mathrm{C}$ and agitated at a speed of $120 \mathrm{rpm}$. Thereafter, $10 \mathrm{~mL}$ of the primary culture was transferred into another $100 \mathrm{~mL}$ of feed medium in a $250 \mathrm{~mL}$ erlenmeyer conical flask and the incubation process was repeated. This was the secondary culture that was used as the inoculum for the degradation studies as this ensures that the organisms had fully adapted to growth on the phenol as sole source of carbon and energy.

\subsection{Analysis Methods}

Growth of the bacteria was monitored by measuring the optical density at 600 $\mathrm{nm}\left(\mathrm{OD}_{600}\right)$ of the culture broth using a spectrophotometer. Phenol concentrations were determined using the 4-aminoantipyrine method [14]. The phenol degradation efficiencies were calculated by the following equation:

$$
R_{V}=\left(T_{1}-T_{2}\right) / T_{1} \times 100 \%
$$

Note that $R_{V}, T_{1}$ and $T_{2}$ represent phenol degradation efficiency, the initial concentration of phenol in medium and the final concentration of phenol, respectively. All samples were analyzed three times to calculate an average value. Statistical analyses were performed by the SPSS and Design Expert, and differences were considered significant at $\mathrm{p}<0.05$.

\subsection{Single-Factor Experiments to Study the Factors Influencing the Phenol Degradation of Strain ZH-1}

Single-factor experiments were conducted for studying the phenol degradation of the strain $\mathrm{ZH}-1$ under different culturing conditions: including glucose concentration, inoculation concentration, $\mathrm{pH}$, and temperature. In inoculation concentration experiments, respectively, inoculate the bacteria suspension $1 \%, 3 \%$, $5 \%, 7 \%, 9 \%, 11 \%$ of the inoculum into a mineral salt medium with glucose concentration of $0.6 \mathrm{~g} / \mathrm{L}$ and phenol concentration of $200 \mathrm{mg} / \mathrm{L}, 35^{\circ} \mathrm{C}, \mathrm{pH}=7,120$ $\mathrm{r} / \mathrm{min}$ shaking culture, samples were taken after $48 \mathrm{~h}$ to analyze the degradation rate of phenol, and three replicates were set for each experiment. Then, the same 
scheme of different experimental conditions ( $\mathrm{pH}$, temperature, glucose concentration) was designed for the experiments.

\subsection{Optimisation Studies}

Box-Behnken design [11] was used for optimization of all the variables. A $3^{\mathrm{k}}$ factorial allows efficient estimation of a second degree quadratic polynomial. Suppose we code the levels in standardized units so that the values taken by each of the variables $X_{1}, X_{2}, X_{3}, X_{4}, \cdots, X_{k}$ are $-1,0$ and 1 and suppose also that the second degree quadratic polynomial fitted by the method of least square is:

$$
Y=b_{0}+\sum_{i=1}^{k} b_{i} X_{i}+\sum_{i=1}^{k} \sum_{i=1}^{k} b_{i j} X_{i} X_{j} \cdots+\varepsilon .
$$

A second order model is got such that the variance of $Y$ is constant for all points equidistant from the center of the design. Where $X_{1}, X_{2}, X_{3}, X_{4}, \cdots, X_{k}$ are the input variables which influence the response $Y ; b_{0}, b_{i}(i=1,2,3,4, \cdots, k), b_{i j}(i$ $=1,2,3,4, \cdots, k, j=1,2,3,4, \cdots, k)$ are known parameters, and $\varepsilon$ is a random error.

Box-Behnken design for four independent variables was taken to obtain the combination of values that optimizes the response within the region of the three dimensional observation space, which allows one to design a minimal number of experimental runs. The model evaluates the effect of each independent variable to a response. The mathematical relationship connecting the variables and the response can be calculated by the quadratic polynomial equation:

$$
\begin{aligned}
Y= & b_{0}+b_{1} X_{1}+b_{2} X_{2}+b_{3} X_{3}+b_{4} X_{4}+b_{11} X_{1}^{2}+b_{22} X_{2}^{2}+b_{33} X_{3}^{2}+b_{44} X_{4}^{2} \\
& +b_{12} X_{1} X_{2}+b_{13} X_{1} X_{3}+b_{14} X_{1} X_{4}+b_{23} X_{2} X_{3}+b_{24} X_{2} X_{4}+b_{34} X_{3} X_{4} .
\end{aligned}
$$

where $Y=$ predicted response; $b_{0}$-constant, $X_{1}=$ glucose concentration $(\mathrm{g} / \mathrm{L}), X_{2}$ = inoculation concentration (\%), $X_{3}=\mathrm{pH}, X_{4}=$ temperature $\left({ }^{\circ} \mathrm{C}\right), b_{1}, b_{2}, b_{3}$ and $b_{4}$-linear coefficients, $b_{12}, b_{13}, b_{14}, b_{23}, b_{24}$ and $b_{34}$-cross product coefficients. The low, middle and high levels of each variable (equally spaced) were designated as $-1,0$, and 1 , respectively, and given in Table 1 . The design experiments were carried out for analysis using Design Expert for the present study, a total of 29 experiments were necessary to estimate the coefficients for the degradation of phenol.

Table 1. Factors and levels of response surface experiments.

\begin{tabular}{ccccc}
\hline Level & $\begin{array}{c}\mathrm{A} \\
\text { Glucose } \\
\text { concentration }(\mathrm{g} / \mathrm{L})\end{array}$ & $\begin{array}{c}\mathrm{B} \\
\text { Inoculation } \\
\text { concentration (\%) }\end{array}$ & $\begin{array}{c}\mathrm{C} \\
\mathrm{pH}\end{array}$ & $\begin{array}{c}\mathrm{D} \\
\text { Temperature }\left({ }^{\circ} \mathrm{C}\right)\end{array}$ \\
\hline-1 & 0.4 & 3 & 6 & 35 \\
0 & 0.6 & 5 & 7 & 37.5 \\
1 & 0.8 & 7 & 8 & 40 \\
\hline
\end{tabular}




\section{Results and Discussion}

\subsection{Phenol Degradation Character of Strain ZH-1 under Various Conditions}

\subsubsection{Effect of Inoculation Concentration}

When the temperature $35^{\circ} \mathrm{C}$, glucose concentration is $0.6 \mathrm{~g} / \mathrm{L}$, and the $\mathrm{pH}=7$, the effect of inoculation concentration on the degradation of phenol and cell growth by strain $\mathrm{ZH}-1$ is shown in Figure 1. With the increase of the inoculation concentration, the degradation of phenol first increased and then decreased. When inoculating a small amount of microorganisms, the degradation effect may not be obvious, but as the amount of inoculation gradually increases, the degradation effect of microorganisms is gradually obvious. When the inoculation concentration was $5 \%$, the degradation rate reached a maximum of $75.4 \%$. When the inoculation amount exceeds $5 \%$, the degradation effect gradually decreases. The possible reason is that with the excessive reproduction of the bacteria in the later stage, the competition of bacteria will lead to the shortage of nutrients, which will slow down the metabolism and growth rate of microorganisms, and affect the absorption and degradation of phenol by the bacteria.

\subsubsection{Effect of Glucose Concentration}

When the temperature $35^{\circ} \mathrm{C}$, inoculation concentration $5 \%$, and the $\mathrm{pH}=7$, the effect of glucose concentration on the degradation of phenol and cell growth by strain $\mathrm{ZH}-1$ is shown in Figure 2. Adding a certain amount of glucose to the mineral salt medium can obviously promote the ability of the strain to degrade phenol. When the glucose concentration is $0.6 \mathrm{~g} / \mathrm{L}$, the degradation of phenol by strain reaches to maximum (76.5\%), which is much higher than the degradation of phenol without adding glucose. When the glucose concentration is more than $0.6 \mathrm{~g} / \mathrm{L}$, as the glucose concentration increases, the phenol degradation shows a downward trend. This may be due to the high glucose concentration, which causes strain $\mathrm{ZH}-1$ to preferentially use glucose, thereby reducing the phenol utilization [15].

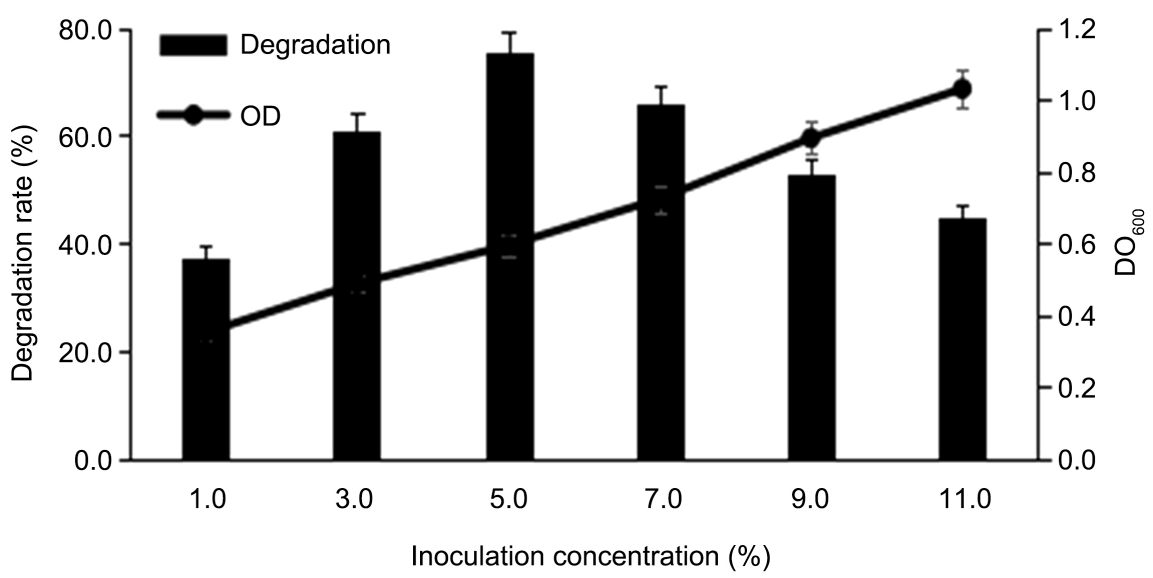

Figure 1. Effect of inoculation concentration on phenol degradation and cell growth by strain $\mathrm{ZH}-1$. 


\subsubsection{Effect of $\mathrm{pH}$}

When the temperature $35^{\circ} \mathrm{C}$ and the glucose concentration $0.6 \mathrm{~g} / \mathrm{L}$, the effect of $\mathrm{pH}$ on the degradation of phenol and cell growth by strain $\mathrm{ZH}-1$ is shown in Figure 3. The strain can degrade phenol better when the $\mathrm{pH}$ is $6-8$, and the degradation rate of phenol is about $70 \%$. However, under strong acid or strong alkali conditions, the strain biodegradation of phenol is inhibited. It may be that strong acid or strong alkali conditions affect the stability of enzymes in organisms and the chemical toxicity of phenol, which changes the binding of substrate molecules and enzymes and affects the degradation of phenol by strain ZH-1 [16].

\subsubsection{Effect of Temperature}

When the $\mathrm{pH}=7$, inoculation concentration $5 \%$ and the glucose concentration $0.6 \mathrm{~g} / \mathrm{L}$, the effect of temperature on the degradation of phenol and cell growth by strain $\mathrm{ZH}-1$ is shown in Figure 4 . When the temperature is $20^{\circ} \mathrm{C}-45^{\circ} \mathrm{C}$, the degradation of phenol is parabolic, and the degradation rate of phenol reaches to maximum $(75 \%)$ at $35^{\circ} \mathrm{C}$. When the temperature is lower or more than $35^{\circ} \mathrm{C}$, the strain $\mathrm{ZH}-1$ degradation ability of phenol decreased, indicating that $\mathrm{ZH}-1$ can degrade phenol well at $35^{\circ} \mathrm{C}$.

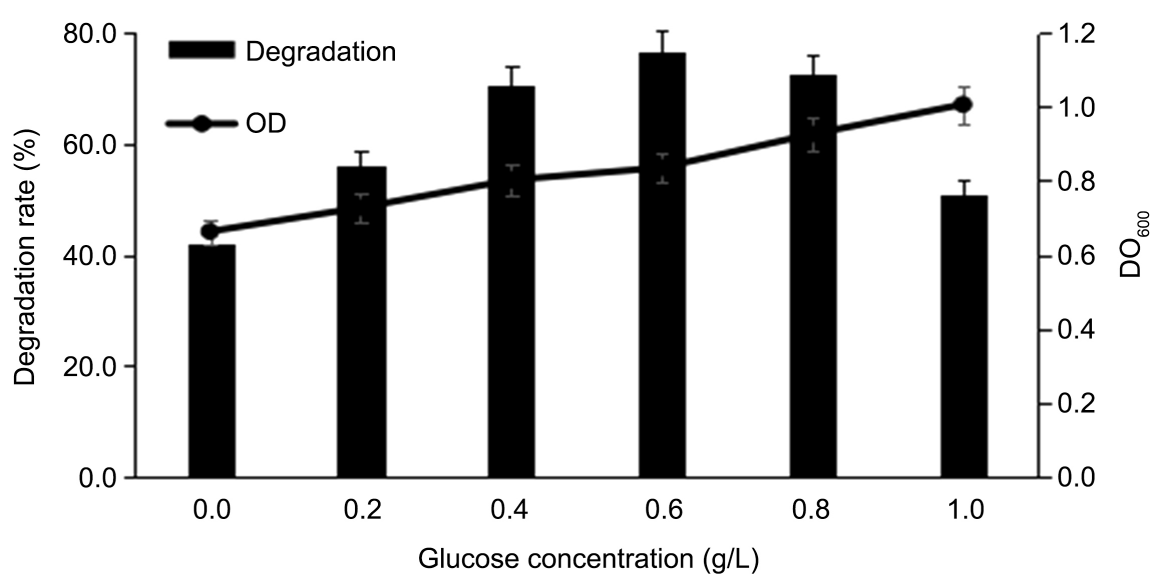

Figure 2. Effect of glucose concentration on phenol degradation and cell growth by strain $\mathrm{ZH}-1$.

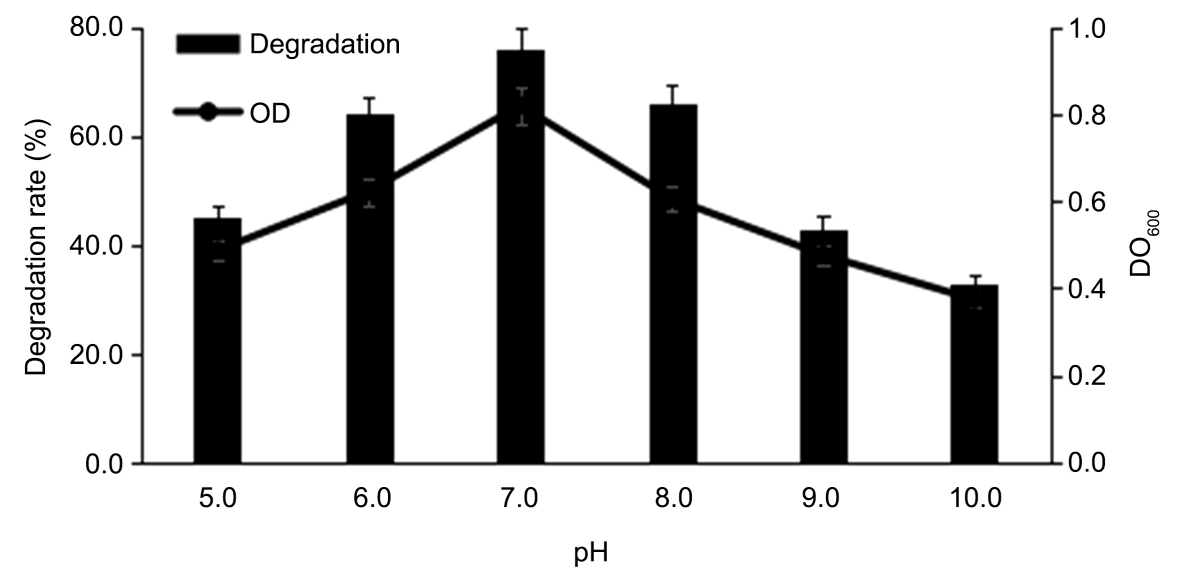

Figure 3. Effect of $\mathrm{pH}$ on phenol degradation and cell growth by strain $\mathrm{ZH}-1$. 


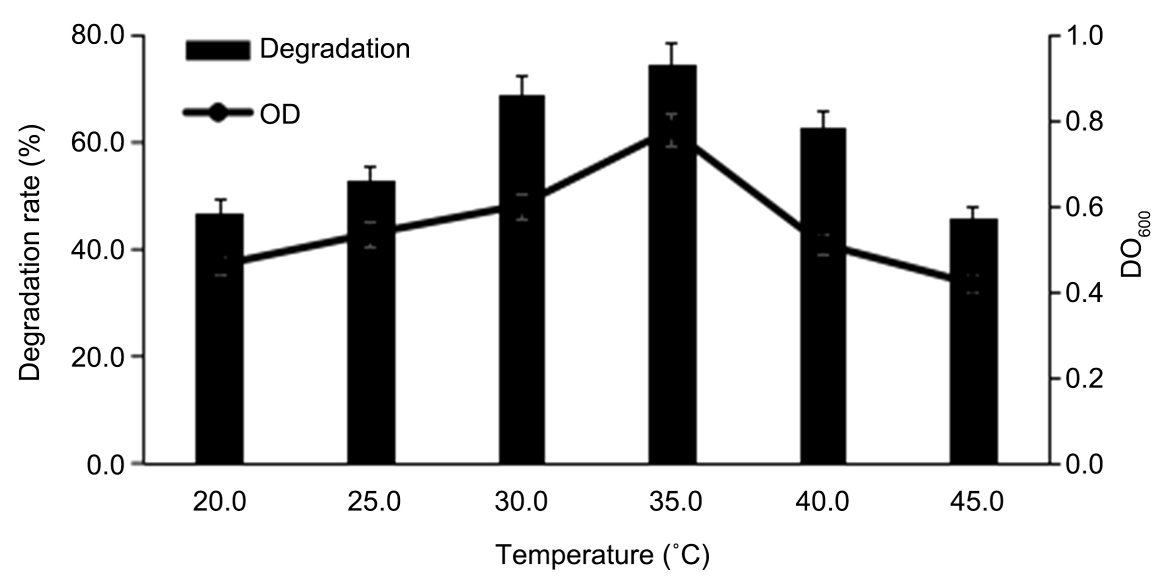

Figure 4. Effect of $\mathrm{pH}$ on phenol degradation and cell growth by strain ZH-1.

\subsection{Optimization of Degradation Conditions of Phenol by Strain ZH-1}

\subsubsection{Model Establishment and Significance Analysis}

Response Surface Methodology is an empirical modelling technique involved in the evaluation of the relationship of a set of controlled experimental factors and observed results. The quantitative description of the process variables effects on phenol microbial degradation was performed [17]. The Response Surface Methodology results and variance analysis were tabulated in Table 2 and Table 3.

The regression equation obtained after analysis of variance gives the level of degradation of phenol as a function of the different process variables: glucose concentration, inoculation concentration, $\mathrm{pH}$ and temperature [16] [18]. All terms regardless of their significance are included in the following equation:

$$
\begin{aligned}
Y= & 90.97+0.14 A+1.26 B-0.11 C-1.64 D-0.065 A B-0.77 A C+0.080 A D \\
& -0.80 B C-1.15 B D-0.25 C D-4.04 A^{2}-5.20 B^{2}-6.13 C^{2}-7.35 D^{2} .
\end{aligned}
$$

where $Y=$ predicted response; $A=$ glucose concentration $(\mathrm{g} / \mathrm{L}), B=$ inoculation concentration (\%), $C=\mathrm{pH}, D=$ temperature $\left({ }^{\circ} \mathrm{C}\right)$

It can be seen from Table 3 that $\mathrm{P}<0.0001$ of the coding equation model indicates that the model is extremely significant. The model lack-of-fit term $\mathrm{P}=$ 0.9957, P > 0.05, and the model lack-of-fit term is not significant, indicating that the experimental results fit well with the mathematical type. The value of $\mathrm{R}^{2}$ indicates a high degree of correlation between the observed value and predicted values. The value of the determination coefficient is a measure of goodness of fit to the mode [17] [18]. The model determination coefficient is $0.9901\left(\mathrm{R}^{2}=\right.$ 0.9901), indicating that the effect of $\mathrm{pH}$, inoculation concentration, glucose concentration and temperature on the degradation of phenol by strain $\mathrm{ZH}-1$ is $99.01 \%$, indicating that the model has a good correlation and can be used to optimize the optimal degradation conditions for the strain to degrade phenol.

\subsubsection{Response Surface Analysis and Determination of Optimal Conditions}

The influence of each factor on the response value may not be a simple linear 
relationship but an extreme point. The response surface graph can directly reflect the interaction between the factors. The contour line can reflect whether the interaction between the two factors is significant. The oval shape of the contour line indicates that the effect between the two factors is significant, and the circular contour line indicates that the effect of the two factors is not significant [18].

Table 2. The actual experimental design and results.

\begin{tabular}{|c|c|c|c|c|c|}
\hline Treatment & A & $\mathrm{B}$ & $\mathrm{C}$ & $\mathrm{D}$ & Y (\%) \\
\hline 1 & 0.4 & 3 & 7 & 37.5 & 80 \\
\hline 2 & 0.8 & 3 & 7 & 37.5 & 80.44 \\
\hline 3 & 0.4 & 7 & 7 & 37.5 & 82.82 \\
\hline 4 & 0.8 & 7 & 7 & 37.5 & 83 \\
\hline 5 & 0.6 & 5 & 6 & 35 & 78.65 \\
\hline 6 & 0.6 & 5 & 8 & 35 & 79.19 \\
\hline 7 & 0.6 & 5 & 6 & 40 & 75.97 \\
\hline 8 & 0.6 & 5 & 8 & 40 & 75.5 \\
\hline 9 & 0.4 & 5 & 7 & 35 & 81.5 \\
\hline 10 & 0.8 & 5 & 7 & 35 & 81.08 \\
\hline 11 & 0.4 & 5 & 7 & 40 & 77.85 \\
\hline 12 & 0.8 & 5 & 7 & 40 & 77.75 \\
\hline 13 & 0.6 & 3 & 6 & 37.5 & 77.56 \\
\hline 14 & 0.6 & 7 & 6 & 37.5 & 81.61 \\
\hline 15 & 0.6 & 3 & 8 & 37.5 & 79.2 \\
\hline 16 & 0.6 & 7 & 8 & 37.5 & 80.05 \\
\hline 17 & 0.4 & 5 & 6 & 37.5 & 80.17 \\
\hline 18 & 0.8 & 5 & 6 & 37.5 & 82.53 \\
\hline 19 & 0.4 & 5 & 8 & 37.5 & 81 \\
\hline 20 & 0.8 & 5 & 8 & 37.5 & 80.27 \\
\hline 21 & 0.6 & 3 & 7 & 35 & 77.83 \\
\hline 22 & 0.6 & 7 & 7 & 35 & 82.58 \\
\hline 23 & 0.6 & 3 & 7 & 40 & 76.95 \\
\hline 24 & 0.6 & 7 & 7 & 40 & 77.1 \\
\hline 25 & 0.6 & 5 & 7 & 37.5 & 90.32 \\
\hline 26 & 0.6 & 5 & 7 & 37.5 & 91.04 \\
\hline 27 & 0.6 & 5 & 7 & 37.5 & 90.32 \\
\hline 28 & 0.6 & 5 & 7 & 37.5 & 90.32 \\
\hline 29 & 0.6 & 5 & 7 & 37.5 & 92.86 \\
\hline
\end{tabular}


Table 3. Results of regression analysis of the Box-Behnken experiment.

\begin{tabular}{|c|c|c|c|c|c|c|}
\hline Source & $\begin{array}{l}\text { Sum of } \\
\text { squares }\end{array}$ & $\begin{array}{l}\text { Degree of } \\
\text { freedom }\end{array}$ & $\begin{array}{l}\text { Mean } \\
\text { square }\end{array}$ & F value & $\mathrm{P}$ value & Significance \\
\hline Model & 644.07 & 14 & 46 & 100.22 & $<0.0001$ & $* *$ \\
\hline A & 0.25 & 1 & 0.25 & 0.54 & 0.4732 & \\
\hline B & 19.20 & 1 & 19.20 & 41.83 & $<0.0001$ & $* *$ \\
\hline $\mathrm{C}$ & 0.14 & 1 & 0.14 & 0.30 & 0.5941 & \\
\hline $\mathrm{D}$ & 32.37 & 1 & 32.37 & 70.53 & $<0.0001$ & $* *$ \\
\hline $\mathrm{AB}$ & 0.017 & 1 & 0.017 & 0.037 & 0.8506 & \\
\hline $\mathrm{AC}$ & 2.39 & 1 & 2.39 & 5.20 & 0.0388 & * \\
\hline $\mathrm{AD}$ & 0.026 & 1 & 0.026 & 0.056 & 0.8167 & \\
\hline $\mathrm{BC}$ & 2.56 & 1 & 2.56 & 5.58 & 0.0332 & * \\
\hline $\mathrm{BD}$ & 5.29 & 1 & 5.29 & 11.52 & 0.0044 & $* *$ \\
\hline $\mathrm{CD}$ & 0.26 & 1 & 0.26 & 0.56 & 0.4684 & \\
\hline $\mathrm{A}^{2}$ & 106.03 & 1 & 106.03 & 230.99 & $<0.0001$ & $* *$ \\
\hline $\mathrm{B}^{2}$ & 175.52 & 1 & 175.52 & 382.36 & $<0.0001$ & $* *$ \\
\hline $\mathrm{C}^{2}$ & 243.89 & 1 & 243.89 & 531.30 & $<0.0001$ & $* *$ \\
\hline $\mathrm{D}^{2}$ & 350.47 & 1 & 350.89 & 763.49 & $<0.0001$ & $* *$ \\
\hline Residual & 6.43 & 14 & 0.46 & & & \\
\hline Lack of fit & 1.58 & 10 & 0.16 & 0.13 & 0.9957 & \\
\hline Pure Error & 4.84 & 4 & 1.21 & & & \\
\hline Cor total & 650.49 & 28 & & & & \\
\hline $\mathrm{R}_{\mathrm{adj}}^{2}=0.9802$ & $\mathrm{R}^{2}=0.9901$ & & & & & \\
\hline
\end{tabular}

Note: ${ }^{*},{ }^{* *}$ respectively indicate significant differences at the $\mathrm{P}<0.05, \mathrm{P}<0.01$ levels.

The coefficient of the model and the corresponding P-values (Table 3 ) suggest that among the test variables, inoculation concentration and temperature are highly significant. These observations can be interpreted as a consequence of proportional relationship between the variables and phenol degradation. The mutual effects of temperature, $\mathrm{pH}$, glucose concentration and inoculation concentration are of equal significance. This data analysis also substantiates the inference that can be drawn from three-dimensional contour plots (3-D graphics) as shown in Figures 5-10, respectively. The interactions among temperature, $\mathrm{pH}$, glucose concentration and inoculation concentration are quite prominent from the elliptical nature of the respective contour plots. These figures also suggest the optimum range of the process variables. 

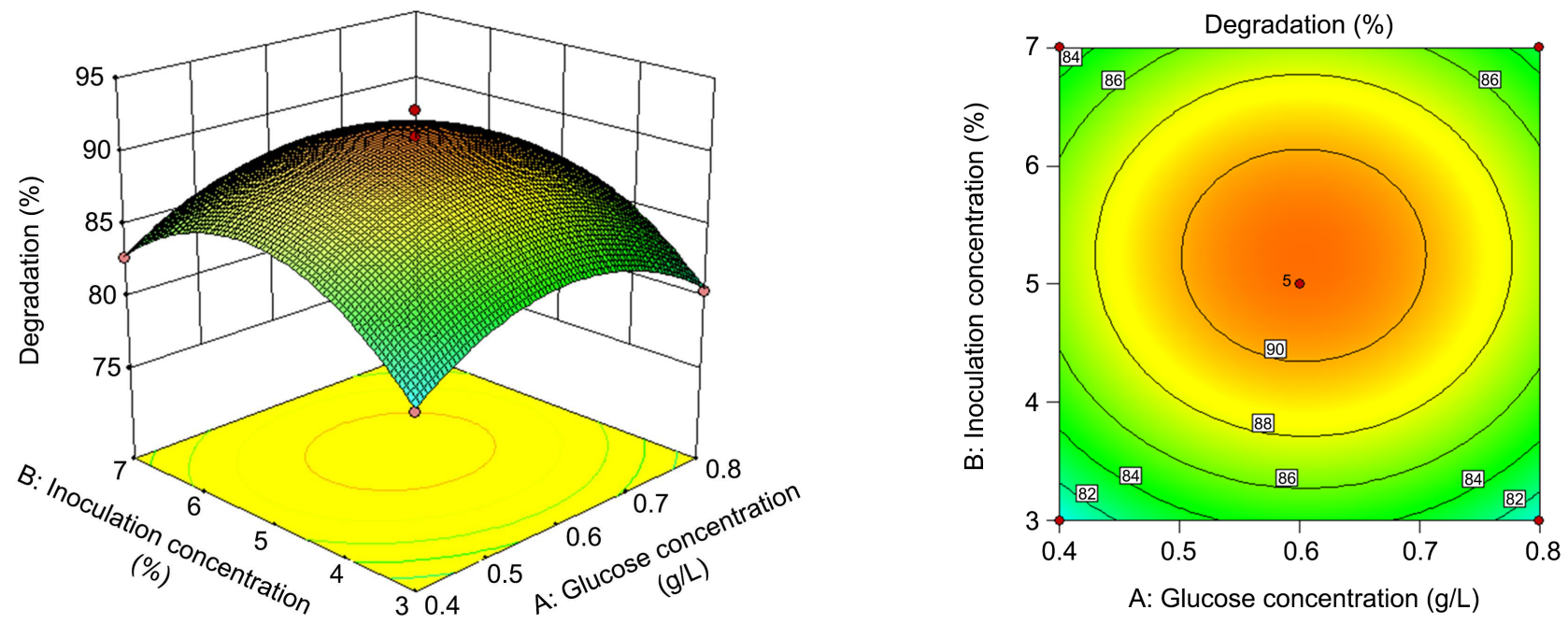

Figure 5. Response surface (left) and contour map (right) of glucose concentration and inoculation concentration.

Figure 5 shows the response surface and contour map of the interaction effect between the glucose concentration and inoculation concentration on degradation of phenol. From the contour map it can be observed that the graphic is close to round. Therefore, the interaction effect of glucose concentration and inoculation concentration is not significant.

Figure 6 shows the response surface and contour map of the interaction effect between the glucose concentration and $\mathrm{pH}$ on degradation of phenol. It is obvious that the $\mathrm{AC}$ interaction curve of the response surface is steep, and the contour map is nearly elliptical, indicating that the impact on phenol degradation is significant.

Figure 7 shows the response surface and contour map of the interaction effect between the glucose concentration and temperature on degradation of phenol. From the contour map it can be observed that the graphic is close to round. Therefore, the interaction effect of glucose concentration and temperature is not significant.

Figure 8 shows the response surface and contour map of the interaction effect between the inoculation concentration and $\mathrm{pH}$ on degradation of phenol. It is obvious that the $\mathrm{BC}$ interaction curve of the response surface is steep, and the contour map is nearly elliptical, indicating that the impact on phenol degradation is significant.

Figure 9 shows the response surface and contour map of the interaction effect between the inoculation concentration and temperature on degradation of phenol. It is quite clear that the BD interaction curve of the response surface is steep, and the contour map is nearly elliptical, indicating that the impact on phenol degradation is the most significant.

Figure 10 shows the response surface and contour map of the interaction effect between temperature and $\mathrm{pH}$ on degradation of phenol. From the contour map it can be observed that the graphic is close to round. Therefore, the interaction effect of temperature and $\mathrm{pH}$ is not significant. 

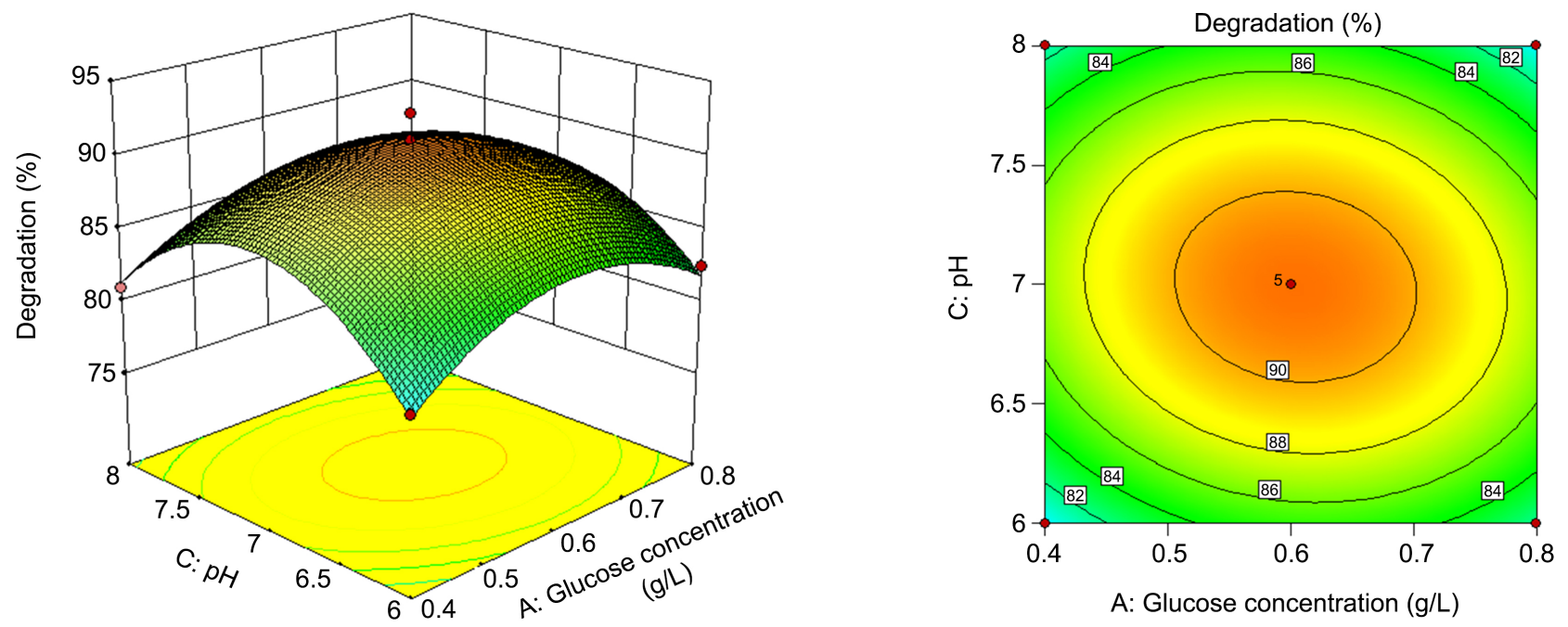

Figure 6. Response surface (left) and contour map (right) of glucose concentration and $\mathrm{pH}$.
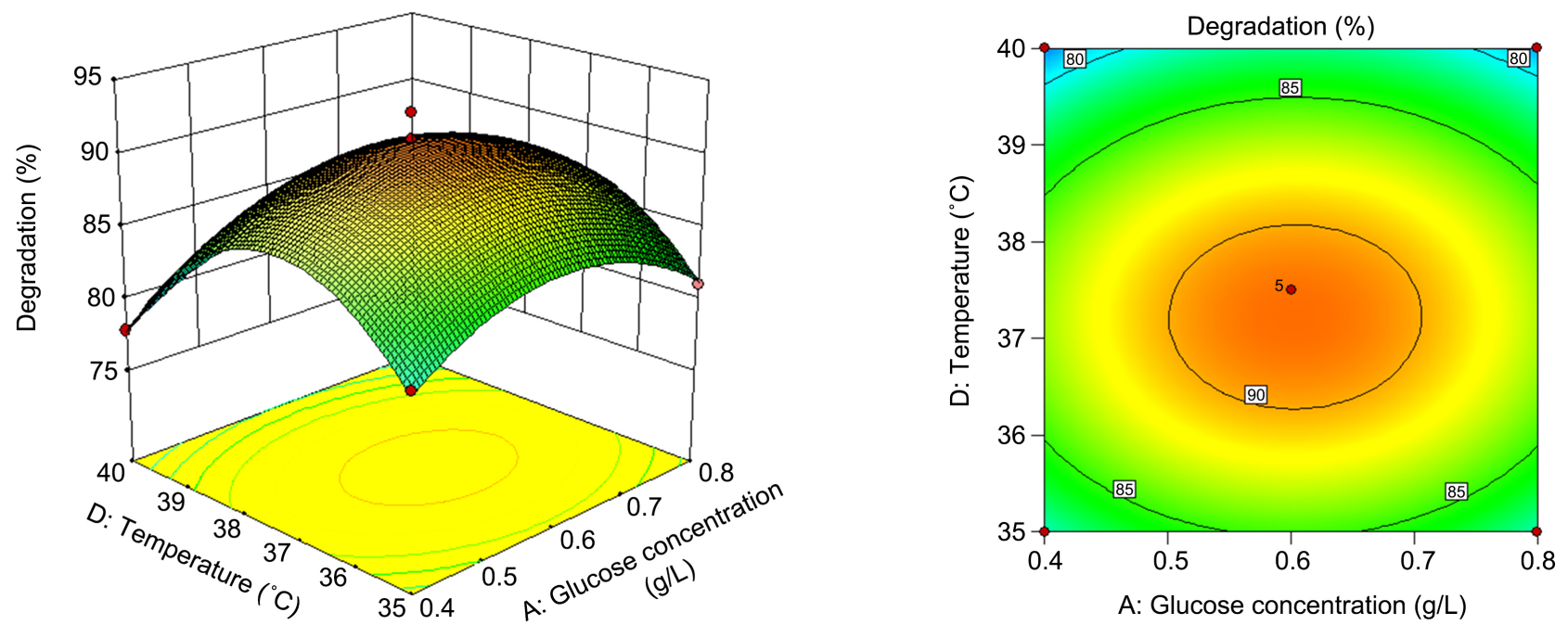

Figure 7. Response surface (left) and contour map (right) of glucose concentration and temperature.
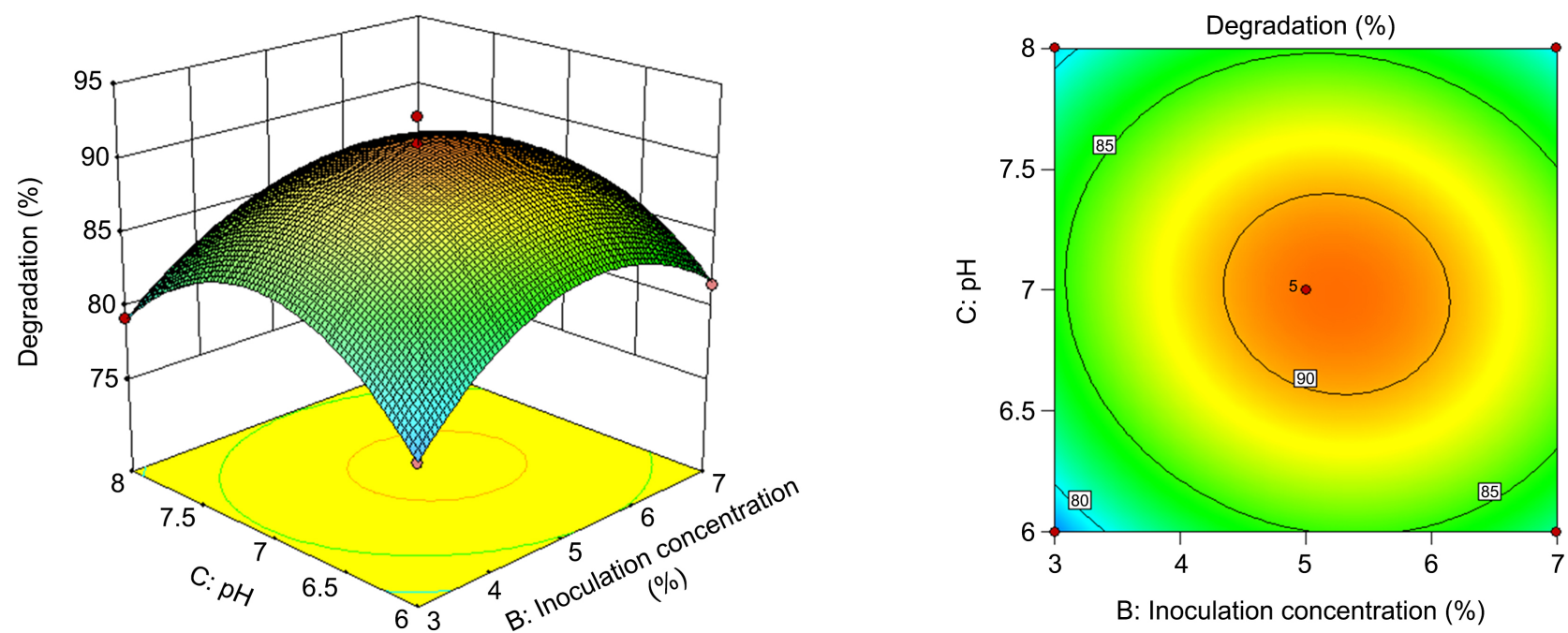

B: Inoculation concentration (\%)

Figure 8. Response surface (left) and contour map (right) of inoculation concentration and $\mathrm{pH}$. 

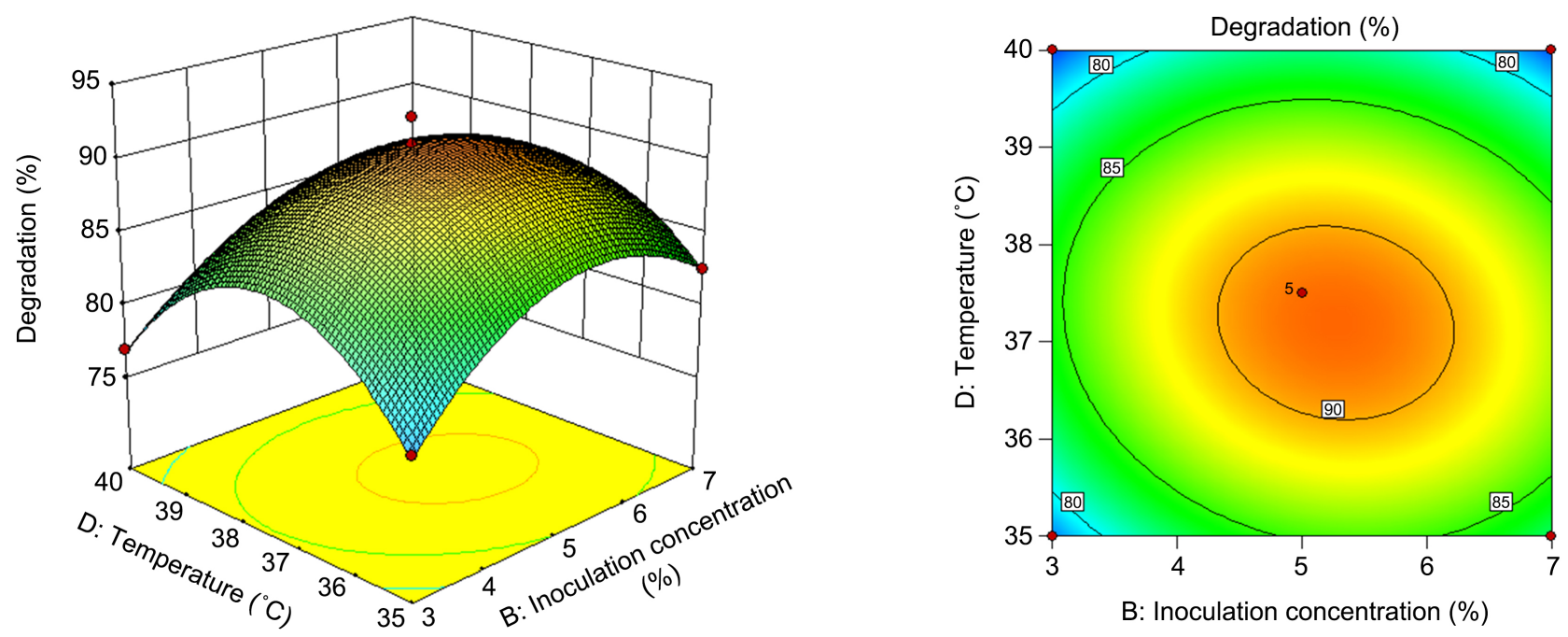

Figure 9. Response surface (left) and contour map (right) of inoculation concentration and temperature.
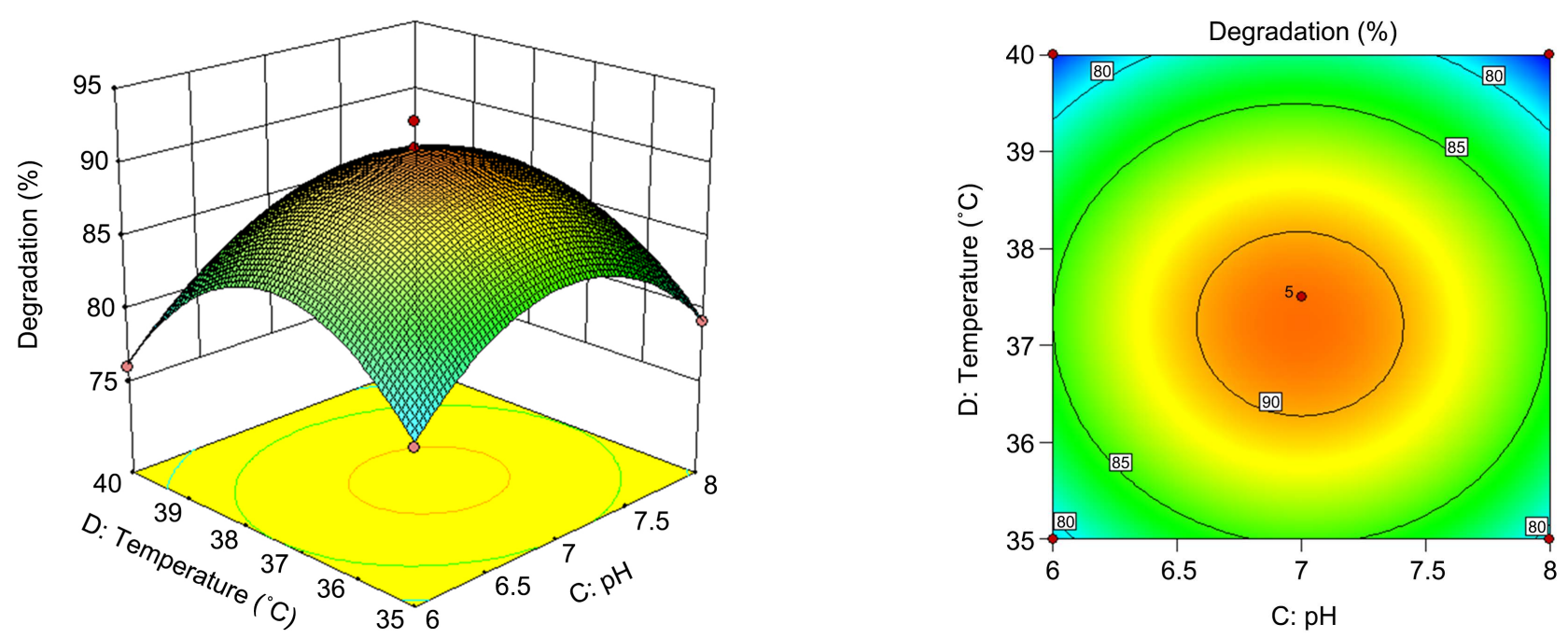

Figure 10. Response surface (left) and contour map (right) of $\mathrm{pH}$ and temperature.

Through the test model and response surface analysis, the best conditions for strain $\mathrm{ZH}-1$ to degrade phenol are temperature $37.19^{\circ} \mathrm{C}$, inoculation concentration $5.098 \%, \mathrm{pH}=6.810$ and glucose concentration $0.688 \mathrm{~g} / \mathrm{L}$. Under these conditions, the predicted value of phenol degradation rate is $90.267 \%$.

\subsection{The Experiment of Model Validation}

In order to test the accuracy of the model prediction, a phenol degradation experiment was carried out under the best predicted conditions: temperature $37^{\circ} \mathrm{C}$, inoculation concentration $5 \%, \mathrm{pH}=7$ and glucose concentration $0.7 \mathrm{~g} / \mathrm{L}$. Strain $\mathrm{ZH}-1$ was inoculated in mineral salt medium containing $200 \mathrm{mg} / \mathrm{L}$ of phenol and cultured at $120 \mathrm{r} / \mathrm{min}$ for 48 hours. The degradation rate of phenol was obtained $89.62 \%$, with little deviation from the predicted value of $90.267 \%$, indicating that the model can effectively optimize and predict the conditions for the strain to degrade phenol. 


\section{Conclusion}

The degradation condition of phenol by $P$. stutzeri $\mathrm{ZH}-1$ was originally isolated and identified from Fenhe River was optimized in laboratory. Single-factor experiments showed that when the $\mathrm{pH}=7$, temperature $35^{\circ} \mathrm{C}$, glucose concentration $0.6 \mathrm{~g} / \mathrm{L}$, and inoculation concentration $5 \%$, as a matter of fact, the degradation effect of phenol by the strain ZH-1 was the best. Response Surface Methodology experiment results in that the optimal conditions for phenol degradation were: temperature $37^{\circ} \mathrm{C}$, inoculation concentration $5 \%, \mathrm{pH}=7$ and glucose concentration $0.7 \mathrm{~g} / \mathrm{L}$; under the conditions, the strain $\mathrm{ZH}-1$ exhibited efficient phenol degradation ability with maximum phenol degradation rate of $89.62 \%$, with little deviation from the predicted value of $90.267 \%$. Therefore, strain $\mathrm{ZH}-1$ was a promising candidate in the extensive application of various pollution control systems including industrial waste water, pharmaceuticals, explosive manufacturing, plastic, petroleum refineries, etc.

\section{Acknowledgements}

This work was financially supported by the Natural Science Foundation Project of Shanxi Province (201801D121206) and the Natural Science Foundation of Modern College of Humanities and Sciences of Shanxi Normal University (2018JCYJC01).

\section{Authors' Contributions}

This work was carried out in collaboration between both authors. Author YY performed the statistical analysis, wrote the protocol and wrote the first draft of the manuscript. Author QPH designed the study, managed the analyses of the study and managed the literature searches. Both authors read and approved the final manuscript.

\section{Conflicts of Interest}

The authors declare no conflicts of interest regarding the publication of this paper.

\section{References}

[1] Kumar, A., Kumar, S. and Kumar, S. (2005) Biodegradation Kinetics of Phenol and Catechol Using Pseudomonas putida MTCC 1194. Biochemical Engineering Journal, 22, 151-159. https://doi.org/10.1016/j.bej.2004.09.006

[2] Kavitha, V. and Palanivelu, K. (2004) The Role of Ferrousion in Fenton and Photo-Fenton Processes for the Degradation of Phenol. Chemosphere, 55, 1235-1243. https://doi.org/10.1016/j.chemosphere.2003.12.022

[3] Santos, V.L.D., Monteiro, A.D.S., Braga, D.T. and Santoro, M.M. (2009) Phenol Degradation by Aureobasidium pullulans FE13 Isolated from Industrial Effluents. Journal of Hazardous Materials, 161, 1413-1420. https://doi.org/10.1016/j.jhazmat.2008.04.112

[4] Saha, N.C., Bhunia, F. and Kaviraj, A. (1999) Toxicity of Phenol to Fish and Aquatic 
Ecosystems. Bulletin of Environmental Contamination and Toxicology, 63, 195-202. https://doi.org/10.1007/s001289900966

[5] Ren, S. and Frymier, P.D. (2003) Toxicity Estimation of Phenolic Compounds by Bioluminescent Bacterium. Journal of Environmental Engineering, 129, 328-335. https://doi.org/10.1061/(ASCE)0733-9372(2003)129:4(328)

[6] Ali, O., Namane, A. and Hellal, A. (2013) Use and Recycling of Ca-Alginate Biocatalyst for Removal of Phenol from Wastewater. Journal of Industrial \& Engineering Chemistry, 19, 1384-1390. https://doi.org/10.1016/j.jiec.2012.12.045

[7] Karatay, S.E. and Dönmez, G. (2014) An Economical Phenol Bioremoval Method Using Aspergillus Versicolor and Agricultural Wastes as a Carbon Source. Ecological Engineering, 73, 224-228. https://doi.org/10.1016/j.ecoleng.2014.09.061

[8] Kurzbaum, E., Raizner, Y., Cohen, O., Suckeveriene, R. Y., Kulikov, A. and Hakimi, B., et al. (2017) Encapsulated Pseudomonas putida for Phenol Biodegradation: Use of a Structural Membrane for Construction of a Well-Organized Confined Particle. Water Research, 121, 37-45. https://doi.org/10.1016/j.watres.2017.04.079

[9] Basak, B., Bhunia, B. and Dey, A. (2014) Studies on the Potential Use of Sugarcane Bagasse as Carrier Matrix for Immobilization of Candida tropicalis PHB5 for Phenol Biodegradation. International Biodeterioration \& Biodegradation, 93, 107-117. https://doi.org/10.1016/j.ibiod.2014.05.012

[10] Annadurai, G., Balan, S.M. and Murugesan, T. (1999) Box-Behnken Design in the Development of Optimized Complex Medium for Phenol Degradation Using Pseudomonas putida (NICM 2174). Bioprocess Engineering, 21, 415-421. https://doi.org/10.1007/PL00009082

[11] Kureel, M.K., Geed, S.R., Giri, B.S., Rai, B.N. and Singh, R.S. (2017) Biodegradation and Kinetic Study of Benzene in Bioreactor Packed with Puf and Alginate Beads and Immobilized with Bacillus sp. M3. Bioresource Technology, 242, 92-100. https://doi.org/10.1016/j.biortech.2017.03.167

[12] Wen, C.F. and Hu, Q.P. (2016) Orthogonal Test Design to Optimize on Ammonium Removal by Pseudomonas stutzeri ZH-1. Journal of Applied Life Sciences, 10, 1-7. https://doi.org/10.9734/JALSI/2017/31281

[13] Zhu, L., Ding, W., Feng, L.J., Kong, Y., Xu, J. and Xu, X.Y. (2012) Isolation of Aerobic Denitrifiers and Characterization for Their Potential Application in the Bioremediation of Oligotrophic Ecosystem. Bioresource Technology, 108, 1-7. https://doi.org/10.1016/j.biortech.2011.12.033

[14] Mu, X.J., Ding, S.X., Zhao, N., et al. (2020) Response Surface Methodology Optimization and Kinetics of Phenol Degradation by Halomonas H17. Environmental Pollution and Control, 42, 449-453+456.

[15] Agarry, S.E., Audu, T.O.K. and Solomon, B.O. (2010) Optimisation of Process Variables for Microbial Degradation of Phenol by Binary Mixed Culture of Pseudomonas aeruginosa and Pseudomonas fluorescens Using Response Surface Methodology. International Journal of Environment \& Pollution, 43, 161-176. https://doi.org/10.1504/IJEP.2010.035921

[16] Mollaei, M., Abdollahpour, S., Atashgahi, S., Abbasi, H., Masoomi, F., Rad, I., Lotfi, A.S., Zahiri, H.S., Vali, H. and Noghabi, K.A. (2010) Enhanced Phenol Degradation by Pseudomonas sp. SA01: Gaining Insight into the Novel Single and Hybrid Immobilizations. Journal of Hazardous Materials, 175, 284-292. https://doi.org/10.1016/j.jhazmat.2009.10.002

[17] Mrozik, A., Miga, S. and Piotrowska-Seget, Z. (2011) Enhancement of Phenol Degradation by Soil Bioaugmentation with Pseudomonas sp. JS150. Journal of Applied 
Microbiology, 111, 1357-1370. https://doi.org/10.1111/j.1365-2672.2011.05140.x

[18] Youssef, M., Ei-Shatoury, E.H., Ali, S.S. and El-Taweel, G.E. (2019) Enhancement of Phenol Degradation by Free and Immobilized Mixed Culture of Providencia stuartii PL4 and Pseudomonas aeruginosa PDM Isolated from Activated Sludge. Bioremediation Journal, 23, 53-71. https://doi.org/10.1080/10889868.2019.1602106 